\section{IN THIS ISSUE}

\section{From the Field}

See our round-up of Title IX news involving postsecondary institutions across the country. This month, we bring you key information on OCR's latest guidance.

\section{Compliance Corner}

Understand Title IX protection of gender identity and gender expression to ensure inclusiveness.

\section{Pages 4-5}

\section{Professional Perspective}

Jyl Shaffer, the University of Cincinnati's Title IX coordinator, provides advice for those who are new to the role.

\section{Resource Alert}

Struggling with climate surveys? An upcoming online training by The NCHERM Group, LLC., titled "Developing and Analyzing Climate Surveys" can help.

\section{ABOUT US}

The NCHERM Group, LLC., a law and consulting firm offering systems-levels solutions to create safer campuses, and the Association of Title IX Administrators, which provides networking and professional development for Title IX coordinators, publish Title IX Today and its companion e-newsletter.

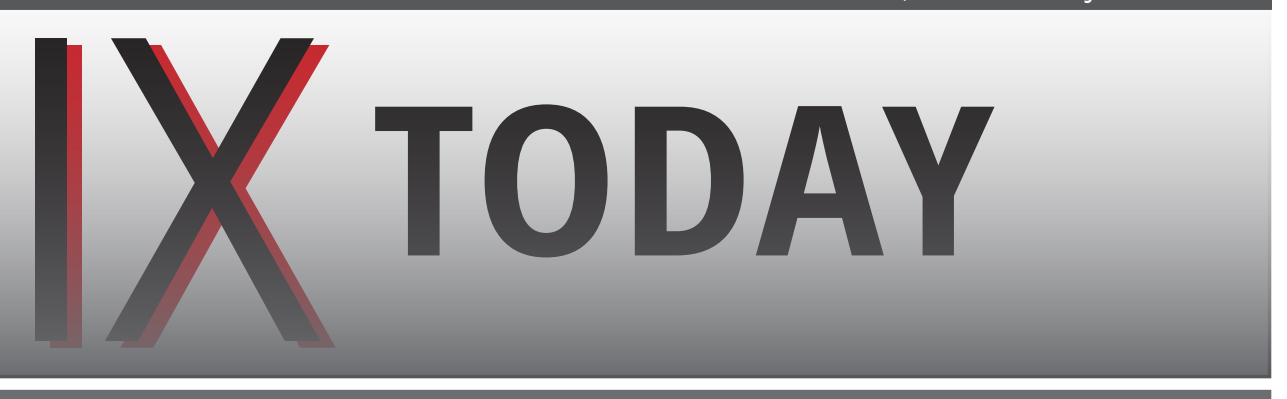

THE LEAD I SEXUAL MISCONDUCT

\title{
Sexual violence awareness, prevention require multifaceted strategy
}

\section{By Jane Alexander}

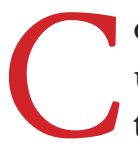

ollege and university leaders are under increased pressure from the media, the public, and government to address sexual violence on their campuses. News headlines about sexual assault scandals on campuses everywhere are raising concern about higher education's immediate and long-term response to the problem.

The Education Advisory Board's Student Affairs Forum
'Our research has uncovered
four critical components
of a comprehensive sexual violence prevention and response strategy for students, faculty, and staff members.'

\section{Establish a task force}

Launching an active and coordinated sexual violence task force is the first step in ensuring robust prevention efforts. Our research reveals, however, that only about 50 percent of institutions have such a task force. But having a task force alone does not guarantee success. We found that at many institutions that have one, the task force is a large and unwieldy body that struggles - Alexander with organizational research has found that institutional responses to sexual violence tend to be decentralized and disorganized. Overworked staff members, individual campus departments, and student groups often run piecemeal prevention programs. But effectiveness in this area requires a comprehensive approach.

Our research has uncovered four critical components of a comprehensive sexual violence prevention and response strategy for students, faculty, and staff members. These practices, explained in depth in our whitepaper, "Building an Effective University Infrastructure: Addressing Sexual Violence on Campus," and summarized here, can help institutions achieve measurable results.
Before establishing a sexual violence task force (or overhauling your current one), consider bringing together a smaller planning group of three to five individuals. This group should steer the larger task force and have the final say in decision-making.

Once the core group is organized, the next step is to identify strategic partners to join the larger task force. Limit your team to no more than 20 members, including the core planning group. While a larger group brings many stakeholder voices to the table, meetings can quickly become freewheeling discussions rather than action-oriented sessions. With 20 individuals or fewer, the group will be Continued on p. 3 


\section{TITLE|X TODAY}

Publisher Brett A. Sokolow, J.D.
Brett@ncherm.org

Editor

Cynthia Gomez, M.A.

Assistant Editor Marianne Price, M.S.
Marianne@ncherm.org

Contributing Editors Leslee Morris, J.D.

Erin Buzuvis, J.D.

sshead-Makar, J.D.

\section{Title IX Today (Print ISSN 2377-} $10.17732 /$ TIXT) is published every month by The NCHERM Group, LLC., 09 Lancaster Ave., Berwyn, PA 19312 \$299: Includes one issue per month,
sent via postal mail and emailed in PDF format, along with additional premiu

TO ORDER:

Phone: (610) $993-0229$

Fax:(610) $993-0228$
Email: Amanda@ncherm.org
URL: www.ncherm.org/store

Postmaster: Send address changes to

Tittle IX Today, The NCHERM Group, LLC.,

Copyright $\odot 2015$ The NCHERM Group, mitted by the 1976 United States Copyright Act, no part of this publication may e reproduced or stored in a retrie system in any form or by any $m$ without prior written permission.
wit.

Reprint requests may be sent directly rization mancherm.org. Reprint autho payment of a per-copy fee to the Co ight Clearance Center, located at 222 Plewo (978) 5 , Danvers, MA 01923 8600; Web: www.copyright com

\section{OCR issues new Title IX guidance}

his spring, the Office for Civil Rights issued three documents: two letters and a "Title IX Resource Guide." If your campus is struggling with compliance with Title IX, these documents could help you gain the support and resources you need to be more effective in your role. It would be wise to take these documents as notice that OCR expects all colleges, universities, and schools to be in full compliance.

DCL restates need

\section{for TIX coordinators} A "Dear Cold their efforts and references a concursupentents and college presidents rently issued resource guide meant to re-states the need for all such institu- help them ensure compliance. The tions to have a designated Title IX co- letter ends with a reminder that OCR ordinator to handle sex- and gender- is there to provide technical assistance based complaints and offenses.

The letter notes the importance of View the letter in its entirety at imbuing that role with authority and www2.ed.gov/about/offices/list/ocr/ providing it with the needed support docs/dcl-title-ix-coordinators-let to ensure effectiveness. It also out- ter-201504.pdf.

lines factors to take into consideration when appointing a Title IX coordinator. Also addressed are issues related to visibility, training, conflict of interest, and protection from retaliation for Title IX coordinators.

Read the letter at www2.ed.gov/ about/offices/list/ocr/letters/colleague 201504 title-ix-coordinators.pdf. $\diamond$

Letter to coordinators recognizes their work

A second letter, issued the same day and aimed at Title IX coordinators, compliance overview

A "Title IX Resource Guide" offers an overview of Title IX requirements, with broad-based information on ath letics, preg It alsors exp he pow Tille IX coordiance for their campuses.

You can check it out and download it at www.edpubs.gov/document/ ed005571p.pdf? $c k=40$.

- Compiled by Cynthia Gomez, Editor

\section{Resource guide provides} It also explins how Tille IX coordinators can help ensure legal compli-
Continued from $p .1$

easier to manage.

At the University of California, Irvine, the core planning gro monthly during the school year and several times over the summer. The planning group defines the broader agenda, explores any changes that need to be made to the task force format, and sets the calendar of task force activities the and meeting, or $\mathrm{Co}$ ordinated Community Response Team, meets for 90 minutes every six weeks. During meetings, department representatives share updates about their work. This approach increases engagement and buy-in, as members are eager to learn from and share with each other. It also ensures the task force is making progress on its goals.

\section{Inventory current efforts}

The task force should inventory current sexual violence prevention efforts on campus. But the process can often be disorganized and time-consuming

To streamline this effort, send out a simple survey to all department heads and ask them to forward it to individuals in their units who do sexual violence programming or other outreach work. Once the task force has a list of all the programming currently happening on campus, it can identify duplicat forts and programming gaps.

\section{Create a one-stop porta}

The task force should educate the campus about the institution's sexual violence policy and ensure that clear and concise information is available. Recent Office for Civil Rights resolutions call attention to the need to have a comprehensive and concise sexual violence website, but most are falling short. While many institutions post their policies and procedures online, the information is often difficult to locate. A student in crisis needs immediate cess to clear and concise information any sites are overloaded ith far too much content that is often confusing and outdated.

The University of North Carolina thapel Hill's sexual violence website is exemplary. Its Web address, safe.unc du, is memorable and easy to display campaign posters and social media. large button on the landing page directs students to information detailing reporting options, including an anonymous online reporting form. The page also provides a link to survivor suports, which are clearly labeled as confidential or non-confidential resources.

Hardwire faculty, staff training

Training faculty and staff is challenging, but failure to educate employees about their role has significant consequences, including OCR investigations and fines, negative publicity, and an exacerbation of the problem.

Georgia Tech University's Gold Folder provides a simple solution to increasing faculty and staff knowledge bout sexual violence. The folder describes the signs of a student who has been sexually assaulted and provides guidance on helping the student and reporting the incident. The folder is available online and a hard copy is mailed all university employees each yea While in an in-person traing or conple ing an online module, the Gold Folde puts easily accessible information about sexual violence into everyone's hands.

Learn more: Established in 2007, $\mathrm{AB}$ is a trusted advisor and performance mprovement partner to $1,000+$ colleges and universities across North Americ and Europe. Through our innovative membership model, we partner wit student affairs leaders at more than 175 nstitutions, helping them solve their most pressing problems. $\diamond$

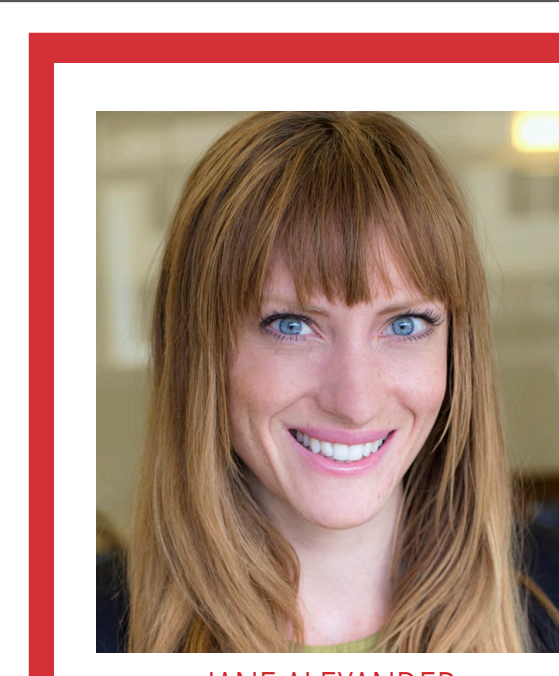

JANE ALEXANDER

ane Alexander is a research consultant with the Student more information, she may be reached at jalexander@ eab.com.

\section{KEY TAKEAWAYS}

Establish a core planning group and campuswide task force to coordinate the institution's prevention and response efforts.

Inventory existing prevention efforts on campus to identify duplicative efforts and programming gaps to strengthen the institution's overall response.

" Create a one-stop Web portal for the campus community with clear, concise, and up-to-date information for students in crisis.

" Provide university employees with an easily accessible, just-in-time resource to enable them to appropriately re spond to students in crisis. 


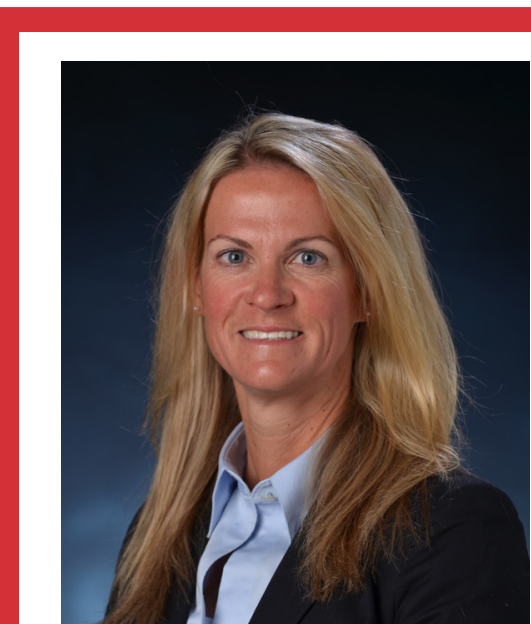

LESLEE MORRIS

Leslee Morris serves as an associate at The NCHERM Group. She was previously the Title IX compliance and grievances coordinator for National University. You may contact her at Leslee@ncherm.org.

\section{KEY TAKEAWAYS}

" Discrimination on the basis of gender nonconformity falls under the purview of Title IX.

" Gender expression is protected as its own category, and not as a by-product of gender nonconformity with gender stereotypes.

" The Department of Education has encouraged the courts to interpret sex discrimination to include discrimination on the basis of gender nonconthe basis of gender noncon-
formity, gender identity, and transgender status.

» Evidence of gender stereotyping may not be necessary to prove that discrimination against a transgender person against a transg
occurred. $\diamond$
COMPLIANCE CORNER I RIGHTS OF TRANSGENDER \& TRANSITIONING INDIVIDUALS

\section{Understand Title IX protection} of gender identity and gender expression

ByLeslee Morris, J.D., ContributingEditor 7 itle IX explicitly prohibits discrimination on the basis of sex The Department of Education through the Office for Civil Rights, has interpreted "on the basis of sex" to include not only sexual harassment, sexual violence, and sexual misconduct, but also relationship violence, stalking, and any other discrimination or harassmen on the basis of sex or gender.

As far back as 2001, OCR indicate (www2.ed.gov/about/offices/list/ocr/docs/ shouide.html) that it similarly considered discrimination on the basis of gender nonconformity to fall under its jurisdic tion, recognizing that gender encompasses the cultural and social aspects associated with masculinity and femininity. Specificlly, OCR wrote, "Title IX also Specifcally, OCR wrote, Title IX also prohibits gender-based harassment in-
cluding verbal, nonverbal or physical agcluding verbal, nonverbal or physical ag-
gression, intimidation or hostility based gression, intimidation or hostility based
on sex or sex stereotyping, even if not on sex or sex stereotyping, even if not sexual in nature, if it rises to a level that in or benefit from the school's program. This interpretation was reinforced in the agency's 2011 guidance (www2 in the agency's 2011 guidance (ww .ed.gov/about/offices/l

colleague-201104html).
Two recent events reflect OCR's Two recent events reflect OCR's
intent to specifically include discrimination based on gender identity an transgender status within the umbrella of discrimination "on the basis of sex," thus clarifying that gender expression is protected as its own category, and not as a by-product of nonconformity with gender stereotypes. First, in early May 2015, OCR released its biannual report (www2 ed.gov/about/reports/annual/ ocr/report-to-president-and-secretaryof-education-2013-14.pdf) summarizing its work during the two previous fisca lution of two cases involving discrimination against transgender students. In one case, a transgender ninth-grader with a male gender identity, who had been living as a boy since fifth grade, filed a complaint alleging that a California school district violated Title IX by denying him access to boys' facilities at school and prohibiting him from sharing a cabin with other boys on a schoolsponsored overnight trip. Pursuant to a voluntary resolution agreement, the district agreed to allow the student to to "otherwise treat the student as a boy in all respects," and to amend its policies relative to other transgender students gender identities. Here, treating transgender student who identifies as male differen gender students who identify as male raised a claim of discrimination on the basis of gender identity, distinct from a claim based on transgression of gender stereotypes.

Similarly, in February of 2015, the Department of Education filed a statement of interest (www .justice.gov/crt/about/edu/documents/tooleysoipdf) in support of a lawsuit filed against a Michigan school district by a sixth-grade student who is transgender. The student alleged that the school refused to refer to him by his male name and pronoun, disallowed him access to the boys' bathroom, and failed to protect him from harassment by his peers. The ED encouraged the court to interpre sex discrimination to include not only discrimination on the basis on gender nonconformity, but also on the basis of gender identity and transgender status. And it's not just OCR. In 2012, the years. The report described OCR's resouse male restrooms and locker rooms,
Equal Employment Opportunity Commission found that a complaint of employment discrimination "based on gender identity, change of sex, and/ or transgender status" fell under the purview of Title VII.

In that case (www.eeoc.gov/decisions/0120120821\%20Macy\%20v\%20 DOF20ATF.txt), Mia Macy, a transgender police detective, was told that she would not be hired for a job that had essentially been promised to her prover was in the process of transitioning was in the process of transitioning from male to female. In determining that the complaint fell within the EEOC's jurisdiction, the agency wrote that "claims of discrimination based on transgender status, also referred to as claims of discrimination based on gender identity, [fall] under Title VII's sex discrimination prohibition." It further delineated that "intentional discrimination against a transgender individual because that person is transgender is, by definition, discrimination based on sex" and that gender-stereotyping evidence is not necessary to prove that transgender person.

transgender person.

h from the Human Rights Campaign, published as a study entitled "Growing Up LGBT in America" (www.hrc.org/youth-report/), reflects what many of us know anecdotally:

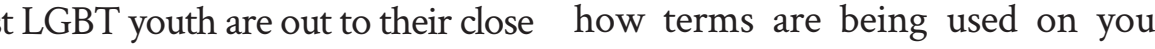
fiends and classmates. Nearly two- campus and in your community, unhirds are out at school. Seventy-five derstanding that terms constantly percent of LGBT youth say that most of evolve. It is also important that you their peers do not have a problem with know the difference between biologiheir identity as LGBT. Despite this ac- cal sex (referring to chromosomes, eptance, LGBT youth are much more hormones, reproductive organs, and likely than their peers to experience ver- genitalia), gender identity (an internal bal harassment, exclusion, and physical sense of gender), gender expression attacks at school. In addition, 78 percent (an outward expression of gender) of transgender Americans say they have and transgender (an umbrella term ox (n) er Law Center (www.transgenderlaw may not match the gender they wer org/resources/transfactsheet.pdf) indicate assigned at birth, whose behavior hat an estimated 2 to 5 percent of the may encompass everything from a population is transgender, meaning boy wearing fingernail polish to indithey experience some degree of gender viduals having surgery to change their dysphoria. Given these numbers, it is sex). Other terms such as cisgender, Title IX process and personnel are spectrum, and a de a part of your canpus culture. It ased on gender nonconformity, gen- is important to recognize that sexual der identity, or transgender status. In orientation refers to whom a person its 2014 Q\&A document (www2.ed.gov/ is attracted, and has little relation to about/offices/list/ocr/docs/qa-201404 gender identity and expression. title-ix.pdf), OCR indicated that schools In addition, it may be helpful to should ensure that staff members who utilize your LGBTQ resource center are responsible for responding to com- on campus or in your community to plaints of sexual violence receive ap- become informed and to help you ropriate training about working with develop a policy and practice that LGBT and gender nonconforming stu- competently addresses complaints dents and same-sex sexual violence. of discrimination based on gender As a Title IX coordinator or in- nonconformity, gender identity, and vestigator, it is crucial that you know transgender status.
Gender inclusiveness, sensitivity, begins with you

emonstrating sensitivity regarding gender identity and expression and transgender status can help you build a rapport with individuals who have Title IX-related grievances and gain their trust. And that can make investigating and resolving reports of gender-based discrimination or misconduct a little less challenging.

" Use inclusive language, regardless of with whom you may be communicating.

» Ask: "How do you identify?" That includes individuals' names, preferred pronouns, relationship status, and gender and sexual orientation of their partners.

" Reflect an individual's preferred name and pronoun in all communication

" Engage in training.

"Use gender-neutral terms in your policies and avoid using gender-normative scenarios.

»Ensure that resource websites, brochures, and intake forms are gender-inclusive or gender-neutral. 


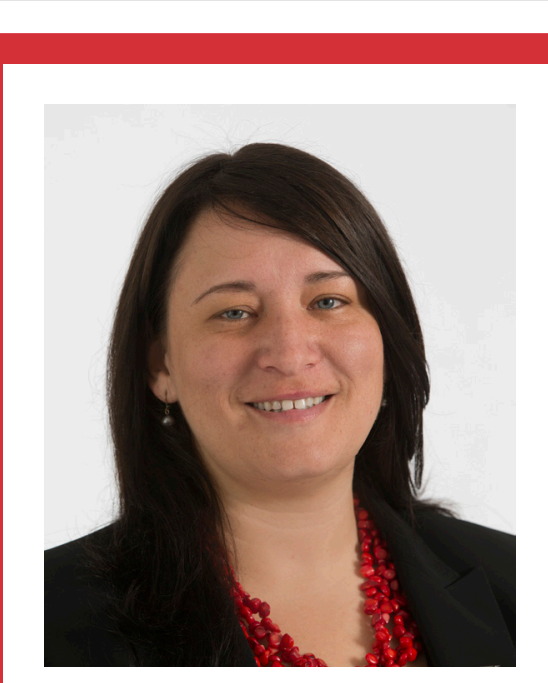

IYL SHAFFER

Jyl Shaffer serves is the Title IX coordinator at the University of Cincinnati. For more inforat/yl.Shaffer@uc.edu.

\section{KEY TAKEAWAYS}

" Get to know those individuals across your campus with whom you may have to work on Title IX cases at some point.

" Find out who is already doing gender-equity work at your institution that inat your institution that in
tersects with your own Title tersects with your own Title
IX work, and find ways to collaborate.

" Look to existing resources in the field, as well as to your own professional experiencown professional experiences to become better at what you do.

" Recognize that your job can be extremely difficult and emotionally draining and take care of yourself to avoid burnout. $\diamond$
PROFESSIONAL PERSPECTIVE I ADMINISTRATION

Advice from a new Title IX coordinator: Connect with others on campus

ByErinBuzuvis, J.D.,ContributingEditor prevention and gender equity work $\mathrm{yl}$ Shaffer is the University of that many dedicated employees, stuCincinnati's first full-time, dedi- dents, and alumni were doing long cated Title IX coordinator. Prior before I got here. Sometimes, folks did to stepping into the role in October the work without having community 2014, Title IX duties had been distrib- with one another. My challenge is to uted between an administrator and keep those people engaged while also staff deputies. She shared her experi- expanding the conversation to includ ence, challenges, and advice with us. the lenses of civil rights and compli-

What experience from prior positions did you bring to the job?

A I started working in violence $A_{\text {prevention - domestic violence }}$ work in particular - in 2004. Working in crisis response, shelter management, court advocacy, and community victim advocacy gave me a strong rasp of not just the issues covered unTite IX, but also the needs of tims and the challenges to "resolving" these kinds of complex issues.

ance and coordinating our efforts.

What experiences and resources have been most helpful in your position?

A I am definitely where I am in part A because of the Association of Title IX Administrators. The trainings, the listserv, and the opportunity to meet other coordinators and professionals working on Title IX have been amaz ing. I still lean heavily on my state dome I s ill lean heavily on my state domestic violence and sexual assault coalitions. They are invaluable resources fo understanding state law and what issues

What was the biggest chal- victims face that may be unique to the lenge you faced off the bat, state or even the local area I'm in. and what challenges are you facing now?

Also, the best collection of domestic violence, sexual violence, and stalking

It's not easy to read a case file and training (on-line and in person) that I've $A_{\text {assess what we're doing when I found is on the National Center on Do- }}$ don't have a clue about who the people mestic and Sexual Violence's site (www involved are and what they do for the $\left.. n c d s v .0 r g / n c d \_u p c o m i n g t r a i n i n g s . h t m l\right)$. university. I made a commitment to Because I ran a shelter, I'm used to meet the people who worked on Title doing a lot of documentation for federal IX and understand their roles, ideas, and and state grants, so being able to adapt concerns. Most of the people I talked to my old case management forms has been

were front-line employees - in particu- great for helping me stay organized.

ar those who work with students dily and are the most likely to hear about issues or be seen as supportive individuals. I wanted to hear not only what we've been doing, but how people have experienced our work.

One current challenge has to do with how to recognize the violence
What advice would you have today for the Jyl who started this job last October?

A It's OK to admit that this work $\mathrm{A}_{\text {is tough, and sometimes it's aw- }}$ ful, and you'll want to quit. We aren't invincible. We often work as armies of one or in environments that don't fully understand what we do or that ask us for quick fixes that don't actually exist. We put on positive faces for our campuses, but it's important to let yourself feel the struggle sometimes.

You can't always make friends with co-workers because of our investigative roles, so it can be lonely. And you'll always have something you should have done yesterday. You have to take care of yourself.

In the past, many institutions have assigned the label of Title IX coordinator to someone on staff simply to satisfy the compliance obligation. Would you agree that the role of Title IX coordinator is having a transformational moment?

Absolutely. Yes, my job is about $A_{\text {compliance. But looking forward }}^{\text {Absolutely. Yes, my job is about }}$ it's also about creating change. If all I do is respond to reports of policy violations (which is historically what we thought the job was about), I'm only doing one part of the job. We are a place to go when someone needs help. We lead when som a neutral place when people who are deeply invested may not be able to take on a neutral role. We model inclusion in the midst of a national dialogue that is becoming increasingly polarized.

My vision is about maintaining strong response procedures AND an office that is proactive. My office has to be deeply invested in the university's vision of itself for the future and taking
vition action to make sure we're an equitable place where that vision can flourish.

What is your strategy for ensuring that everyone knows about your position, understands your role, and is comfortable contacting you when needed?

A During my first six months here, A Ive conducted approximately 60 outreach activities, from facilitating TiIX trainings to tabling at other campus events. I have also met with at least ozen students individually who reprent different communities on campus.

We are also creating curriculum fo a "Safe Zone"-style training for faculty and staff who want to be more engaged in receiving reports from students and colleagues, and we're putting together a Title IX brown bag lunch series specifically for faculty. On June 23, well each-ins for the campus community.

I go to sports events, guest lectures, and other activities on campus not only so members of the campus can get to know me, but also so I can get to know hem. And we work with campus parters who do education on parallel issues (e.g., alcohol awareness, feminism, an cmpus safety) so that we deliver a common message.

You are one of my favorite Twitter follows. Can you decribe your professional relationship with social media?

\section{TITLE IX TODAY \\ SUBSCRIBE TODAY}

$\square$ Yes, I'd like a one-year subscription to Title IX Today, which includes one eight-page issue per month, in print and PDF, along with access to additional all for just $\$ 299$

Simply fill out this subscription coupon with your information and payment option, and mail it to us at: The NCHERM Group, LLC., 1109 Lancaster Ave., Berwyn, PA 19312. Make checks payable to The NCHERM Group, LLC.

Name:

Title:

$\square$ Check is enclosed.

$\square$ Amex $\square$ MC $\square$ Visa

Card \#:

Mailing Address:

Expiration:

Cardholder Name:

$\overline{\text { Signature: }}$

Email:

Phone:
For payment questions, please email Marianne@ncherm.org. 


\section{Learn to successfully conduct climate surveys}

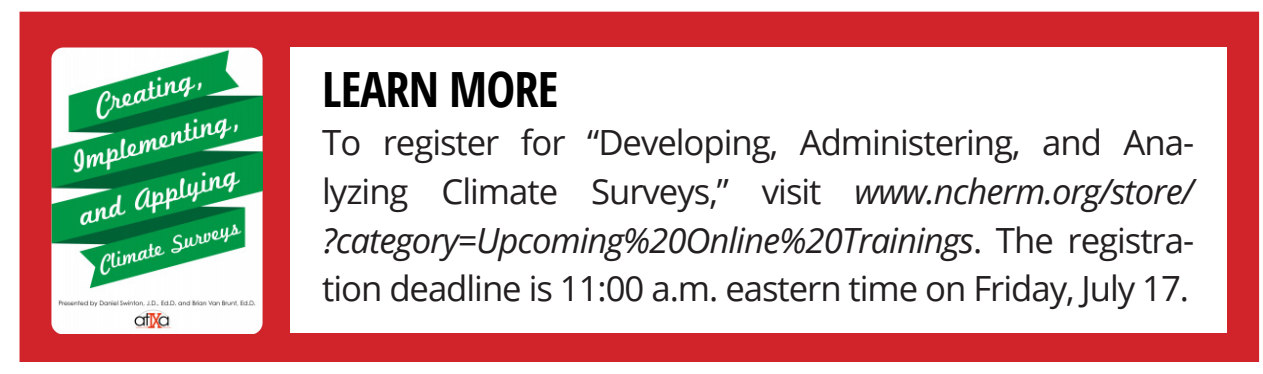

\section{By Cynthia Gomez, Editor}

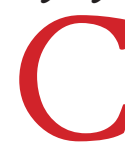

limate surveys can help you create a safer, more equitable, and welcoming campus environment by showing you where improvement is needed and demonstrating your institution's commitment to curbing sexual misconduct. If your institution is not conducting climate surveys, it's time to start. Both the Office for Civil Rights and the White House Task Force to Protect Students from Sexual Assault have urged institutions to do so.

While many templates exist for conducting such surveys, not all are research-based. Some don't use validated questions. And some even use victimblaming language. Yet creating a survey instrument that offers sound question design and addresses climate issues holistically can be a daunting challenge.

Join the Association of Title IX Administrators in "Developing, Administering and Analyzing Climate Surveys," an Online Training taking place from 1:00 - 2:30 p.m. eastern time on Friday, July 17.

The presenters will address everything from the parameters and limitations of a well-designed and useful survey tool, to how to best mobilize members of the campus community to participate. They will review current guidance on conducting climate surveys; the pros and cons of existing and forthcoming climate survey templates; and how to translate climate survey findings into strategic planning and action steps. $\diamond$

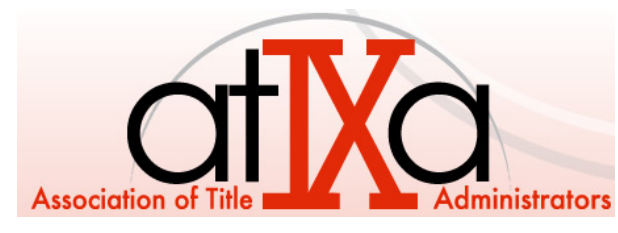

